\title{
The greying intensivist: ageing and medical practice - everyone's problem
}

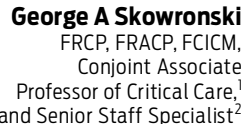

Carmelle Peisah

MB BS(Hons)

MD, FRANZCP

Conjoint Associate

Professor of Psychiatry, and Senior Visiting Medica

Officer $^{3}$

1 University of New South Wales, Sydney, NSW.

2 Intensive Care Unit, St George Hospital, Sydney, NSW.

3Bankstown Hospital, Sydney, NSW.

g.skowronski@ unsw.edu.au

MJA 2012; 196: 505-507 doi: 10.5694/mjall.11579

\section{Work and retirement patterns of older doctors}

In 2009, a CICM workforce survey (personal communication, Felicity Hawker, Director of Professional Affairs, CICM) showed that intensivists over 55 years of age intended to practise an average of only a further 2.1 years full-time and 2.4 years part-time. They cited excessive oncall, callback and after-hours work as negative influences on their desire to continue working. South Australia had the highest proportion of older intensivists (24\%), while Queensland had the lowest (10\%). Intensivists aged over 55 years spent less time on call in public hospitals (68.5 hours/ month compared with an overall mean of 106 hours/ month), while practising at the same level as younger intensivists in the private sector. This private sector drift among older doctors has been reported previously. ${ }^{8}$ The trend of intensivists retiring early or changing to less stressful areas of medicine is not restricted to Australia and, in the US, has led to concerns about future workforce shortages. ${ }^{9}$

\section{Health and impairment of older doctors}

Doctors have above-average health, commensurate with their socioeconomic status, and are less likely to suffer lifestyle-related illnesses, such as heart and smokingrelated diseases. ${ }^{10}$ However, depression and anxiety are common among doctors, and the suicide rate is higher in some groups of doctors, such as anaesthetists, than in the general population. ${ }^{10}$ Although the prevalence of impairment among intensivists is not known, related specialties Reflections p 528
Perspective $p 498$

\section{Summar}

The medical profession is ageing in parallel with the wider community, with more Australian doctors working into their 70s. This has implications for workforce planning and raises questions about competence. However, no Australian specialist college has policies relating to the special circumstances of ageing practitioners.

- Ageing practitioners are affected by a number of agerelated sensory and neurocognitive changes, including a decline in processing speed, reduced problem-solving ability and fluid intelligence, impaired hearing and sight, and reduced manual dexterity.

- A policy of mandatory retirement is not consistent with the wide individual variations in cognitive ageing. However, there may be an age ceiling, which varies by medical specialty and individual.

- Studies show that older doctors in several specialties perform worse than their younger colleagues. Older doctors, many of whom are found to be cognitively impaired, are more likely to be reported to the authorities for poor performance.

- The wisdom and experience of older doctors is of great value. However, work adaptations may need to be considered. For intensivists, these could include parttime work towards retirement, reduced after-hours call and shift work, and reduced exposure to acute crisis intervention, with an increased focus on mentoring, teaching, administration and research.

such as anaesthesia and emergency medicine have the highest rates of substance misuse, due to a high-risk working environment, easy access to drugs and premorbid personality traits. ${ }^{11}$ Some subgroups may be at greater risk of poorer health and wellbeing, such as those working in rural and remote areas, or those working excessive hours or shift work with little leave. ${ }^{12}$ Doctors are vulnerable to stress, ${ }^{13}$ contributed to by increased workload, lack of control over work-life balance, professional and social isolation, the demands of rapid developments in medical knowledge, and changes in the health system and community expectations.

Many of these circumstances apply to intensivists, who have been found to suffer from high levels of burnout due to emotional exhaustion and depersonalisation. ${ }^{14,15}$ Encounters with patients and their families in emotionally charged, critical or end-of-life settings can be particularly draining for doctors.

As doctors age, both the nature of stressors and patterns of impairment evolve. These range from the challenges of patient care, teaching, administration and professional development to family and caring responsibilities. ${ }^{16}$ Older 
doctors also have increased frequencies of chronic disease, for which they require independent primary care, with good compliance, and the avoidance of self-treatment and informal consultations. Older doctors are at risk of the "four Ds": depression, drink, drugs and dementia. Of 41 doctors aged over 60 years who were referred to the New South Wales Medical Board Impaired Registrants Program, ${ }^{17}$ 22\% had depression, 29\% suffered from substance use, 54\% had cognitive impairment and $12 \%$ had dementia.

However, this represents a small subset and there is also evidence that older doctors fare better psychologically than their younger colleagues or previous cohorts. This evidence suggests that older doctors view their identity and responsibilities to the profession differently from previous generations, with improved work-life balance ${ }^{18}$ and lower levels of psychological distress and burnout. ${ }^{8}$

\section{Neurocognitive changes and performance}

In exploring the needs of ageing doctors, it is crucial to understand the age-related sensory and cognitive changes that may affect their performance. These include declines in fluid intelligence (adaptive thinking and critical reasoning), processing speed, episodic memory (incorporating personally experienced events), hearing, visual acuity, depth perception, colour discrimination and manual dexterity. ${ }^{19}$

When doctors referred for competency assessment or impairment by regulatory bodies are tested, attentional and executive functions, episodic memory, problem solving and speed of information processing are often found to be impaired, while verbal skills and semantic memory (knowledge of facts, words and meanings) are often intact. ${ }^{19,20}$ This means that doctors with impairment may present well, and cognitive impairment may only be evident on neuropsychological testing, rather than on bedside screens such as the mini-mental state examination. ${ }^{17}$

Changes in processing speed and memory are inevitable and affect even the best performers as they age. ${ }^{21}$ This may be particularly pertinent to intensivists, who rely on rapid decision making and response. However, some data suggest that older doctors are superior at particular tasks (eg, making initial diagnoses) that use non-analytic diagnostic strategies such as pattern recognition, although at times this can be at the risk of premature diagnostic closure. ${ }^{22}$

In terms of performance, older doctors are more likely to be investigated and disciplined by licensing bodies, ${ }^{23}$ more likely to be represented among those referred for competency assessments (specifically associated with cognitive impairment $)^{20}$ and, according to most studies, perform worse than younger doctors in many areas. ${ }^{2}$ Years of clinical experience were negatively related to performance, attributed to a lack of receptiveness in older physicians to new therapies, standards of care, and practice innovations that involve theoretical shifts. ${ }^{2}$

One study found that surgeons aged over 60 years have higher operative mortality than their younger counterparts for complex procedures such as pancreatectomy or cardiac bypass, ${ }^{6}$ especially where procedure volumes were low. However, another study ${ }^{7}$ found that senior surgeons performed at or near the level of younger peers on cognitive tasks.

Low procedure volume and task complexity are recurrent themes in the associations between ageing and poor performance in doctors. Yet, doing fewer complex procedures is an often recommended workplace adaptation for older doctors. It is difficult to strike a balance between minimising case load and maintaining expertise.

\section{Solutions}

\section{Mandatory retirement}

In Australia, other professions have dealt with the issue of the ageing practitioner by mandating retirement at a specific age: for example, 72 years for judges, and 65 years for pilots, who also undergo physical and mental examinations every 6 months from 40 years of age. The medical profession has to date avoided such measures.

Few authors support this draconian approach, which is inconsistent with human rights policies and the government objectives that support workforce participation among ageing people. Moreover, mandatory retirement does not fit well with our understanding of cognitive ageing, which, although ultimately universal, is highly variable in onset and severity. ${ }^{21}$

Nevertheless, it is likely that there is an age ceiling to medical practice, and that this ceiling is different for different medical specialties and for different individuals. Arguments for a set retirement age include the frequent loss of insight ${ }^{17}$ accompanying cognitive decline and the reluctance of some doctors to relinquish their medical identity.

\section{Competency assessment}

An alternative to mandatory retirement is competency assessment, which has been adopted in Ontario, where there are mandatory peer assessments every 5 years for physicians aged over 70 years, and in British Columbia. ${ }^{24}$ Although competency assessment for monitoring performance has been much discussed in the literature, ${ }^{25}$ there has been no consensus about the best methods. Limitations of methods such as universal continuing education requirements and peer review include lack of rigour for peer-review groups, reliance on self-identified problems for discussion, and the difficulty of approaching or reporting senior incompetent peers. While intensivists often work in group environments - where incidental and informal peer reviews occur almost continuously, avoiding the common problem of solo practice associated with undetected impairment ${ }^{17}$ — they are not immune.

\section{Retention strategies}

Another alternative to mandatory retirement is to maximise the value of the older intensivist by supporting areas of decline while capitalising on the older doctor's strengths, trading off the benefits of experience against declining stamina and performance.

Retention strategies or "transitional phase" activities include undergraduate and cross-disciplinary teaching, clinical auditing, research, tribunal work, voluntary work, 
minor procedures, medicolegal work, mentoring, and practice visiting. ${ }^{26}$

\section{Workplace adaptation}

Doctors identified as ageing well by their peers have been found to adopt changes intuitively, such as taking longer with patients, avoiding isolation and areas of unfamiliar practice, retiring from new procedural work and using "scaffold" strategies to support memory. ${ }^{26}$ Potential workplace adaptations have also been identified by a study investigating cognitive changes in older physicians, ${ }^{22}$ but such adaptations need to be individualised and, ideally, would be agreed by each specialty and ratified by the relevant college. Some of adaptations recommended by the American College of Emergency Physicians (the only body to have taken this approach) include weekend day shifts instead of night shifts, consistent shifts at a set time of day or night, fewer consecutive shifts, and exchange of clinical duties for teaching or administration. ${ }^{5}$

Since a detailed review by Baker in $2001^{27}$ of the effects of ageing on the performance of anaesthetists, there has been periodic discussion within the Australian and New Zealand College of Anaesthetists about the role of the older anaesthetist. Baker's recommendations included reducing night-call duties at 55 years of age, ceasing night calls and reducing overall hours at 60 years of age, and mandatory retirement at 65 years of age. However, none of these have yet been implemented as policy by the College. Morgan ${ }^{28}$ has also advocated ceasing after-hours calls for intensivists over 60 years of age, with increased senior registrar cover. A multicentre study in the US is investigating ways to make intensivists' work more sustainable (eg, alternative staffing models such as weekend cross-coverage for a colleague on call during the week). ${ }^{9}$

As far as we are aware, neither the Australian Health Practitioner Regulation Agency nor any of the specialist medical colleges in Australia have any explicit policies regarding ageing practitioners, apart from ethical guidelines regarding doctors' health.

\section{Planning, insight and the group ethos}

Older doctors deemed to be ageing well share insight ${ }^{27}$ into the effects of ageing on practice, the need for adaptations in working hours and choice of work, long-term retirement planning including financial planning, the usefulness of a transitional phase to ease into retirement, and the need to cultivate a variety of medical and non-medical pursuits and relationships early in one's career.

The different stages of a medical career need to be acknowledged. Any workplace adaptations for ageing physicians, especially those involving relinquishing on-call burdens and other onerous aspects of practice, need college ratification and acceptance by all members of the specialty, with the recognition that all will "have their turn". At the same time, we should be wary of workplace changes that create age discrimination against older and comparatively less active employees whose privileges are threatened, as has occurred elsewhere. ${ }^{24}$

\section{Conclusion}

With the general trend towards a longer working life for doctors and the general community, a number of questions need to be addressed by the CICM, by other colleges, by medical boards, and by the medical profession in general. How do we encourage workforce participation and deal with projected workforce shortages? What strategies can be designed to retain older intensivists and other doctors in a safe and sustainable manner, without engendering resentment or hostility from younger professionals and without age discrimination?

There can be no doubt that the professional lifestyle of the typical intensivist has an impact on his or her health and wellbeing, and this may well become more important with ageing. In addition, there are potentially important considerations in relation to patient safety, which may be affected by age-related cognitive and performance changes.

Competing interests: No relevant disclosures.

Provenance: Not commissioned; externally peer reviewed.

1 Australian Institute of Health and Welfare. Medical labour force 2008. Canberra: AlHW, 2010. (AlHW. Cat. No. AUS 131; Bulletin No. 82.) http://www.aihw.gov.au/publication-detail/?id=6442468395\&tab=2 (accessed Mar 2012)

2 Choudhry NK, Fletcher RH, Soumerai SB. Systematic review: the relationship between clinical experience and quality of health care. Ann Intern Med 2005; 142: 260-273.

3 Schofield DJ, Beard JR. Baby boomer doctors and nurses: demographic change and transitions to retirement. Med J Aust 2005; 183: 80-83.

4 Adsett J, Roddis M. Do senior doctors need career development? BMJ Careers 2005; 26 Nov. http:// careers.bmj.com/careers/advice/view-article.html?id=1301 (accessed Mar 2012).

5 American College of Emergency Physicians. Considerations for emergency physicians in pre-retirement years. Ann Emerg Med 2009; 54: 641.

6 Waljee JF, Greenfield LJ, Dimick JB, Birkmeyer JD. Surgeon age and operative mortality in the United States. Ann Surg 2006; 244: 353-362.

7 Drag LL, Bieliauskas LA, Langenecker SA, Greenfield LJ. Cognitive functioning, retirement status, and age: results from the Cognitive Changes and Retirement among Senior Surgeons study. J Am Coll Surg 2010; 211: 303-307.

8 Peisah C, Latif E, Wilhelm K, Williams B. Secrets to psychological success: why older doctors might have lower psychological distress and burnout than younger doctors. Aging Ment Health 2009; 13: 300-307.

9 Garland, A. Multicentre Intensivist Weekend Scheduling Study 2010. http://clinicaltrials.gov/ct2/show/ NCT01145443 (accessed Mar 2012).

10 Carpenter LM, Swerdlow AJ, Fear NT. Mortality of doctors in different specialties: findings from a cohort of 20000 NHS hospital consultants. Occup Environ Med 1997; 54: 388-395.

11 Baldisseri MR. Impaired healthcare professional. Crit Care Med 2007; 35 (2 Suppl): S106-S116.

12 Australian Medical Association. Health and wellbeing of doctors and medical students - 2011. http:// ama.com.au/node/6551 (accessed Mar 2012).

13 Riley GJ. Understanding the stresses and strains of being a doctor. Med J Aust 2004; 181: 350-353.

14 Guntupalli KK, Fromm RE Jr. Burnout in the internist-intensivist. Intensive Care Med 1996; 22: 625-630.

15 Shehabi Y, Dobb G, Jenkins I, et al, Burnout syndrome among Australian intensivists: a survey. Crit Care Resusc 2008; 10: 312-315.

16 Dobb G. Stresses change, but do not go away. Australian Medicine 2009; $21: 12$.

17 Peisah C, Wilhelm K. Physician don't heal thyself: a descriptive study of impaired older doctors. Int Psychogeriatr 2007; 19: 974-984.

18 Australian Medical Association. Work-life flexibility survey: report of findings. Canberra: AMA, 2008. http:// ama.com.au/node/4168 (accessed Mar 2012).

19 Peisah C, Willhelm K. The impaired ageing doctor. Intern Med J 2002; 32: 457-459.

20 Turnbull J, Cunnington J, Unsal A, et al. Competence and cognitive difficulty in physicians: a follow-up study. Acad Med 2006; 81: 915-918.

21 Christensen H. What cognitive changes can be expected with normal ageing? Aust NZ J Psychiatry 2001; 35 : 768-775.

22 Eva KW. The aging physician: changes in cognitive processing and their impact on medical practice. AcadMed 2002; 77 (10 Suppl): S1-S6.

23 Khaliq AA, Dimassi H, Huang CY, et al. Disciplinary action against physicians: who is likely to get disciplined? Am J Med 2005; 118: 773-777.

24 Collier R. Diagnosing the aging physician. CMAJ 2008; 178: 1121-1123.

25 Finucane PM, Bourgeois-Law GA, Ineson SL, Kaigas TM; International Performance Assessment Coalition. A comparison of performance assessment programs for medical practitioners in Canada, Australia, New Zealand, and the United Kingdom. Acad Med 2003; 78: 837-843.

26 Peisah C, Gautam M, Goldstein MZ. Medical masters: a pilot study of adaptive ageing in physicians. Australas J Ageing 2009; 28: 134-138.

27 Baker AB. The ageing anaesthetist. In: Riley R, editor. Australasian Anaesthesia 2001. Melbourne: Australian and New Zealand College of Anaesthetists, 2001: 1-12.

28 Morgan TJ. How long should you work as an intensive care consultant, and should there be consultant shift work? In: Proceedings of the College of Intensive Care Medicine Australian Scientific Meeting 2011 - Pushing the Boundaries of Intensive Care. Melbourne: College of Intensive Care Medicine, 2011: 36-39. 
Clinical focus

INSIGHT

508 MJA $196(8) \cdot 7$ May 2012 